\title{
A LIBERDADE RELIGIOSA COMO DIREITO FUNDAMENTAL
}

Ana Carolina Greco Paes

Discente do Curso de Direito das Faculdades Integradas Antônio Eufrásio de Toledo (SP). E-mail: paes.anac@gmail.com

\section{RESUMO}

O presente artigo visa analisar o porquê do direito à liberdade religiosa ser considerado um direito fundamental no ordenamento jurídico brasileiro. Para embasar tal afirmação foi analisado o que os doutrinadores entendem por direito fundamental, foi feito um comentário a respeito da evolução história dos direitos fundamentais como gerações, dando especial ênfase a primeira geração dos direitos. Por fim foi analisado o que caracteriza um direito como fundamental que são as seguintes características: a aplicação imediata deste direito, ter ele hierarquia constitucional e ter sido uma opção política do legislador enquadrar esse direito como tanto. Além disso, o direito a liberdade religiosa é um direito fundamental que pode se manifestar como liberdade de consciência quando o indivíduo opta por não ter religião. Com base nessas afirmações a liberdade religiosa foi enquadrada como direito fundamental. Palavras-chave: Direito fundamental; direito dos homens; gerações de direitos; liberdade religiosa; liberdade de consciência.

\section{MÉTODOS}

A pesquisa bibliográfica foi o principal meio de obtenção de informações neste trabalho, bem como a jurisprudência e considerações históricas. Em um estudo partindo do raciocínio hipotético dedutivo foram construídas as bases do trabalho.

\section{INTRODUÇÃO}

Afim de que seja possível vislumbrar a liberdade religiosa como direito fundamental, tornase necessário explicar o que são direitos fundamentais segundo a doutrina brasileira e estrangeira. Para tanto será utilizada a visão de doutrinadores, bem como apreciações dos dispositivos consultados no artigo para essa tarefa.

Os direitos fundamentais, inicialmente foram divididos em três gerações, de acordo George Marmelstein quem desenvolveu a "teoria das gerações dos direitos" foi Karel Vasak, jurista tcheco, naturalizado Francês. (2009, p. 40)

Perfilha-se para os fins que este artigo o aspecto tridimensional adotado por Ingo Wolfgang Sarlet. A liberdade religiosa se enquadra como direito de primeira dimensão, ao invés de gerações. (1998, pag. 48) 
As duas primeiras dimensões que tratam respectivamente, da liberdade e igualdade, possuem caráter individual, em detrimento ao foco coletivo. Houve necessidade de limitar o poder do Estado sobre o indivíduo, justamente porque a positivação dos direitos fundamentais é necessária para que não ocorra abuso, por parte dos governantes, na limitação da fruição de tais direitos pelos indivíduos. O indivíduo possui direitos e deve saber quais são para que assim possa torná-los efetivos. (BONAVIDES, 2000, p. 517).

Em seu estudo, Celso Lafer afirma que a proclamação dos direitos humanos nasce quando a lei "passa a ser o homem e não mais o comando de Deus ou os costumes". (1988, pag. 123) 0 homem emancipado e isolado em sociedades secularizadas, necessitava um porto seguro, um direito sólido, positivado, alienado da religião. A incerteza de um "direito divino", monopolizado pela religião, não dava garantias aos indivíduos de que o devido processo legal seria efetuado de forma justa, embasado em leis elaboradas tendo em vista o indivíduo e não somente o bem estar do governante. (MARMELSTEIN, 2009, p. 42)

No cenário acima descrito é que a liberdade religiosa se tornou direito de primeira dimensão. Teve como pano de fundo histórico uma grande ruptura religiosa no ocidente, com as reformas de Calvino e Lutero. A Igreja Católica Apostólica Romana - que por muitos anos ditou como deveria ser, não apenas o direito, mas a vida em sociedade como um todo - perde seu poder com a reforma religiosa, que fez surgir uma nova e diferente forma de pensar. (MARMELSTEIN, 2009, p. 43)

As estruturas da sociedade ocidental foram alteradas, pois essa ruptura religiosa contribuiu para mudanças econômicas, culturais e, principalmente, socais. Os puritanos queriam que o Estado não levasse em conta suas crenças religiosas, sendo por isso um direito negativo. Além dos direitos de liberdade, a primeira dimensão dos direitos alcançou os direitos políticos, que tinha por principal finalidade o exercício democrático do poder e direitos civis.

Feitas tais considerações passa-se a tratar do que vem a ser direitos fundamentais. De acordo com explanação feita por José Afonso da Silva, a expressão que melhor define direitos fundamentais é "direitos fundamentais do homem". (2000, pag. 178)

Direitos fundamentais do homem constitui a expressão mais adequada a este estudo, porque, além de referir-se a princípios que resumem a concepção do mundo e informam a ideologia política de cada ordenamento jurídico, é reservada para designar, no nível do direito positivo, aquelas prerrogativas e instituições que ele concretiza em garantias de uma convivência digna, livre e igual de todas as pessoas. No qualificativo fundamentais acha-se a indicação de que se trata de situações jurídicas sem as quais a pessoa humana não se realiza, não convive e, às 
vezes, nem mesmo sobrevive: fundamentais do homem no sentido de que a todos, por igual, devem ser, não apenas formalmente conhecidos, mas concreta e materialmente efetivados.

Para Patrícia Elias Cozzolino de Oliveira o direito fundamental depende não só do bem que o direito visa proteger, mas também do contexto histórico no qual ele se insere e o fato de estar na Constituição. (2010, pag. 46 /47)

Para nós são direitos fundamentais aqueles pertinentes às pessoas visando o desenvolvimento máximo de suas potencialidades, promovendo a igualdade e a dignidade humana, assegurados pela Norma Fundamental que é a Constituição, mediante proteção especial.(...). Importante lembrar a característica da historicidade dos direitos fundamentais, ou seja, decorrem de uma cadeia evolutiva, pois em determinada época se entenderá determinado direito, como é o caso da liberdade de religião, como fundamental, mas em outra, o mesmo direito não era reconhecido. Logo, os direitos fundamentais dependerão, necessariamente, do caráter histórico do Estado Nacional que os cunhou constitucionalmente.

Dessa forma, tem-se que direitos fundamentais são aqueles que disciplinam a vida do ser humano, direitos inerentes a condição de ser humano, os quais conferem ao indivíduo uma vida digna, e que também demonstram a opção política adotada pelo legislador. A dignidade da pessoa humana é o ponto de partida e a razão da criação das "cartas de direitos".

Alguns doutrinadores, como Jónatas Eduardo Mendes Machado, entendem que os direitos humanos surgem de uma visão cristã do mundo. Este autor, afirma que os direitos humanos nascem da concepção judaico cristã onde declara ter sido o homem criado à imagem e semelhança de Deus. Partindo desse pressuposto é possível afirmar que o homem tem dignidade e esta dignidade deve ser protegida. (2012, pag. 37)

A dignidade da pessoa humana é um atributo universal próprio do ser humano, de procedência transcendente, que gera uma pretensão universal de reconhecimento, respeito e proteção tenho como destinatários todos os indivíduos e todas as formas de poder político e social. Foi isso que esteve em causa quando, no século XVI, na cidade espanhola de Valladolid, os dominicanos Bartolomeu de las Casas e Juan Ginés de Sepúlveda, discutiram entre si a dignidade dos índios americanos. Nesse célebre debate, a teologia bíblica da dignidade natural de todos os seres humanos, criados à imagem de Deus, triunfou sobre os argumentos aristotélicos, considerados à época mais racionais, secularizados e científicos, que viam na escravatura um estado ou predisposição natural de alguns seres humanos. 
De forma didática George Marmelstein afirma que para definir um direito como fundamental, no Brasil, basta que ele tenha três características, quais sejam: aplicação imediata, ser cláusula pétrea e possuir hierarquia constitucional. (2009, p. 17)

\section{INTERPRETAÇÃO DOS DIREITOS FUNDAMENTAIS}

Os direitos fundamentais possuem natureza variada de difícil definição. Existem perspectivas sob as quais eles podem ser analisados, o direito fundamental sempre será o mesmo, seu conteúdo básico não é variável, porém, dependendo da forma como é analisado, há diferentes aspectos do direito que ficam evidentes, como por exemplo a fruição destes.

Para fins deste artigo foram citados alguns autores que observaram o direito fundamental quanto ao poder, ao aspecto objetivo e a função do direito fundamental.

\section{Quanto ao poder}

Segundo a classificação de Celso Lafer, existem duas perspectivas sob as quais os direitos fundamentais podem ser interpretados, a saber: "ex parte populi - a dos que estão submetidos ao poder - e a perspectiva ex parte principis- a dos que detêm o poder e buscam conservá-lo" (1988, p. 125).

A ex parte populi tem raiz no direito natural - trata-se de direitos que nascem com o indivíduo, que existem desde sempre. São considerados direitos inerentes ao indivíduo independentemente de positivação. A perspectiva ex parte principis, tem origem na "governabilidade de um conjunto de homens e coisas num dado território" (LAFER, 1988, p. 126). Dessa forma, quem interpreta o direito é o governante, que levará em conta a população, para que o direito fundamental seja efetivado. O governante deve respeitar o direito fundamental e aplicar a razoabilidade "levando-se em conta os recursos disponíveis e a necessidade de evitar, com a discórdia excessiva a desagregação da unidade do poder." (LAFER, 1988, pag. 126)

Ao analisar o direito fundamental sob estas perspectivas, surgem questões atinentes à fruição de tais direitos. Em relação a ex parte populli Celso Lafer define. (1988, pag. 128 e 129)

$\mathrm{Na}$ perspectiva ex parte populi, que é a da liberdade, uma das contradições, na prática, da tutela, resulta do fato de os direitos de primeira geração almejarem limitar os poderes do Estado, demarcando com nitidez a fronteira entre o Estado e sociedade, e os direitos de segunda geração exigirem a ampliação dos poderes do Estado. É por essa razão que são distintas as técnicas jurídicas que ensejam a fruição, ex parte populi, dos direitos de primeira e de segunda geração 
Quanto a ex parte principis, o governante se preocupa com a ordem que deve ser mantida frente aos direitos que surgem com a primeira dimensão, tais como a liberdade religiosa, de reunião e o direito de fazer greve. O governante deve limitar minimamente tais direitos a fim de viabilizar a vida em sociedade de forma organizada.

\section{Quanto ao aspecto objetivo}

A classificação feita com base no aspecto objetivo dos direitos fundamentais ainda não possui grande expressão no ordenamento pátrio, mas a doutrina estrangeira se ocupa de discussões importantes sobre o assunto. Em relação à sua terminologia será levado em consideração o estudo feito por Ingo Wolfgang Sarlet (1998, pag. 143)

Os direitos fundamentais não se limitam à função precípua de serem direitos subjetivos de defesa do indivíduo contra atos do poder público, mas que, além disso, constituem decisões valorativas de natureza jurídicoobjetiva da Constituição, com eficácia em todo o ordenamento jurídico e que fornecem diretrizes para os órgãos legislativos, judiciários e executivos.

O fato dos direitos fundamentais serem caracterizados por uma perspectiva jurídicoobjetiva implica em desdobramentos importantes no que diz respeito aos limites e restrições de tais direitos. Esse caráter objetivo dos direitos fundamentais influência o Estado a não levar em conta somente o indivíduo, mas a coletividade.

Com base nesta premissa, a doutrina alienígena chegou à conclusão de que a perspectiva objetiva dos direitos fundamentais constitui função axiologicamente vinculada, demonstrando que o exercício dos direitos subjetivos individuais na qual se encontra inserido e da qual não pode ser dissociado, podendo falar-se, neste contexto, de uma responsabilidade comunitária dos indivíduos (SARLET, 1998, pag. 146).

José Joaquim Gomes Canotilho afirma que a fundamentação objetiva visa o significado do direito fundamental para a coletividade e não somente para o individuo. O contrário ocorre na fundamentação subjetiva que busca os interesses apenas do individuo. (2002, pag. 1124).

Os direitos fundamentais no tocante ao exercício devem ser amplos, mas podem ser limitados no caso concreto, uma vez que afetam a coletividade. Podem até ser bloqueados pelo Poder Judiciário, com a finalidade de assegurar algo maior, como a segurança da sociedade. 


\section{Quanto à função}

Por fim, os direitos fundamentais podem ser interpretados levando em conta suas funções, que segundo Canotilho são quatro: função de defesa ou de liberdade; prestação social; proteção perante terceiros e da não discriminação. (2002, p. 407-410).

Em relação à função de defesa ou de liberdade Canotilho afirma. (2002, pag. 407).

Os direitos fundamentais cumprem a função de direitos de defesa dos cidadãos sob uma dupla perspectiva: (1) constituem, num plano jurídico objetivo, normas de competência negativa para os poderes públicos, proibindo fundamentalmente as ingerências destes na esfera jurídica individual; (2) implicam, num plano jurídico - subjetivo, o poder de exercer positivamente direitos fundamentais (liberdade positiva) e de exigir omissões dos poderes públicos de forma a evitar agressões lesivas por parte dos mesmos (liberdade negativa).

Quanto à prestação social é a possibilidade do individuo obter algo através do Estado como a saúde, segurança, educação. Já a proteção perante terceiros, tem-se que o Estado deve promover a proteção dos cidadãos contra eventuais agressões em relação ao direito fundamental que o Estado Ihe garante. (CANOTILHO, 2002, p. 408-418).

Por fim há a função da não discriminação "a doutrina deriva esta função primária e básica dos direitos fundamentais: assegurar que o Estado trate os seus cidadãos como cidadãos fundamentalmente iguais." (CANOTILHO, 2002, p. 409)

Segundo Canotilho estás são as quatro funções de um direito fundamental e conforme será demonstrado a liberdade religiosa se enquadra em todas elas.

\section{CONCLUSÃO}

A liberdade religiosa se enquadra como direito fundamental de primeira dimensão, uma vez que nasceu como liberdade oponível contra o Estado, como direito negativo para proteger o cidadão contra as ingerências do Estado lhe garantindo liberdade no aspecto de sua vida religiosa.

A liberdade religiosa como direito fundamental de primeira dimensão faz com que o Estado garanta ao indivíduo a possibilidade de escolher a religião que quer pertencer, da mesma forma que Ihe garante os aspectos religiosos ligados a esse direito, tais como a liberdade de culto, liturgia.

Esta liberdade é um direito fundamental pois assim é descrita na Constituição Federal do Brasil e faz parte da vida do ser humano, da condição de ser humano. Aqueles que optam por não 
ter religião são abarcados pela liberdade de consciência que lhes garante o direito de professar nenhuma fé.

Em relação à interpretação dos direitos fundamentais, em relação ao poder, a liberdade religiosa é um direito natural, nasce com o homem, pois o homem pode ansiar por ter algo que lhe transcende a existência e buscar tal resposta na religião (ex parte populi).

Já em relação a ex parte principis a liberdade religiosa se caracteriza de forma que os governantes, o Estado deve interferir minimamente nesse direito do cidadão, de forma que somente em casos extremos é que tal liberdade pode ser cerceada.

Quanto ao aspecto objetivo do direito fundamental à liberdade religiosa traz implicações. Pode-se colocar este aspecto, de forma resumida, como se todo o direito fundamental além de ser um direito fosse também um dever. $O$ fato de ser direito fundamental implica ter o aspecto objetivo que lhe gera um dever. Um exemplo onde isto fica claro é a liberdade de culto (que é uma forma de manifestação da liberdade religiosa) não poder afetar o sossego dos moradores das redondezas de um local de culto.

Quanto às funções dos direitos fundamentais a liberdade religiosa se enquadra nas quatro: quais sejam:: função de defesa ou de liberdade; prestação social; proteção perante terceiros e da não discriminação.

A função de defesa ou de liberdade quando o cidadão tem o direito de exigir do Estado que não interfira no aspecto religioso de sua vida e de que interfira positivamente para que lhe garanta o pleno exercício desse direito.

Já na prestação social o Estado fornece meios de que a liberdade religiosa possa ser tutelada quando, por exemplo, concede imunidade tributária aos templos de qualquer culto (artigo 150, VI, "b" da Constituição Federal).

A proteção perante terceiros, tem-se que o Estado deve promover a proteção dos cidadãos contra eventuais agressões que possam advir da sua opção religiosa. No Brasil há um cenário pluralista em relação às religiões, dessa forma, o Estado deve se manter o mais neutro possível no tocante a não ser tendencioso a qualquer religião.

Deve ainda promover a tolerância de todas as religiões para que não haja abuso de direito, do próprio Estado e dos cidadãos em suas relações. Além disso, não deve haver nenhum tipo de discriminação, por motivo religioso, que é onde se enquadra a terceira função da liberdade religiosa como direito fundamental. 
Desta forma fica claro que a liberdade religiosa é um direito fundamental por ser um direito inerente ao homem, por opção política do legislador que elencou tal direito como fundamental em nossa Constituição e por ter aspectos de direito fundamental tais como aplicação imediata, ser cláusula pétrea e ter hierarquia constitucional.

\section{BIBLIOGRAFIA}

BONAVIDES, Paulo. Curso de direito constitucional. 10. ed., rev., atual. e ampl. São Paulo: Malheiros, 2000. 793 p. ISBN 85-7420-205-3.

CANOTILHO, J. J. Gomes. Direito constitucional e teoria da constituição. 6. ed. Coimbra: Almedina, 2002. 1506 p. ISBN 972-40-1806-7.

LAFER, Celso. A reconstrução dos direitos humanos: um diálogo com o pensamento de Hannah Arendt. São Paulo: Companhia das Letras, 1988. 406 p. ISBN 978-85-7164-011-5.

MACHADO, Jónatas Eduardo Mendes. Estado constitucional e neutralidade religiosa: entre o teísmo e o (neo) ateísmo. Porto Alegre: Livraria do Advogado, 2013. 183 p. ISBN 9788573488258.

MARMELSTEIN, George. Curso de direitos fundamentais. São Paulo: Atlas, 2009. 552 p. ISBN 97885-224-5135-7.

MENDES, Gilmar Ferreira. Direitos fundamentais e controle da constitucionalidade: estudos de direito constitucional. 4. ed. rev. e ampl. São Paulo: Saraiva, 2012. 803 p. ISBN 9788502134263. http://dx.doi.org/10.11117/9788565604048

OLIVEIRA, Patrícia Elias Cozzolino de. A proteção constitucional e internacional do direito á liberdade de religião. São Paulo: Verbatim, 2010. 127 p. ISBN 978-85-61996-27-7.

SARLET, Ingo Wolfgang. A eficácia dos direitos fundamentais. 1. ed. Porto Alegre: Livraria do Advogado, 1998. 386 p. ISBN 85-7348-069-6.

SILVA, José Afonso da.Curso de direito constitucional positivo. 17. ed., rev. e atual. nos termos da reforma con São Paulo: Malheiros, 2000. 871 p. ISBN 8574201502.

SORIANO, Aldir Guedes. Liberdade religiosa no direito constitucional e internacional. São Paulo: Ed. Juarez de Oliveira, 2002. 195 p. ISBN 85-7453-247-9. 